\title{
Dobutamine Stress Echocardiography
}

\author{
David S. Bach, MD, and William F. Armstrong, MD
}

Two-dimensional echocardlodraphy is a versatlle, accurate, and readity avallable method for the assessment of cardiac anatomy and function, and extensive experience has been gained in the analysis of left ventricular wall motion. Using modem imaging techniques, regional as well as dobal wali motion analysis can be performed. Echocartiography can bo used in conjunction with a protocol for either exercise or phammacologfc cardiovascular stress in order to identity the distribution and severity of coronary artery dsease, with the induction of a reglonal wall motion abnommally bohis a sign of myocardlal ischemia. The use of dobutamine infusion to accomplish stress echocardiography is a safe, accurate, and practcal method for the dlagnosis of coronary artery disease in patients unable to exercise. In addition to the evaluation of inducBble ischemia, preliminary work is being performed with dobutamine stress echocardiography for the assessment of risk and patient prognosis following acute myocardial infarction and as an indication of tissue viabilty for myocardum that remains dysfunctional at rest following thrombolytic therapy.

(Am J Cardlol 1992;69:90H-96H)

From the Division of Cardiology, Department of Medicine, University of Michigan, Ann Arbor, Michigan.

Address for reprints: William F. Armstrong, M.D., UH B1F245-Box 0022, 1500 E. Medical Center Drive, Ann Arbor, Michigan 48109-0022. $\longrightarrow$ chocardiography is a versatile, accurate, and readily available method for the evaluation of cardiac anatomy and function. Used in conjunction with excrcise or pharmacologic stress protocols, modern 2-dimensional echocardiographic techniques can readily assess regional as well as global left ventricular (LV) function, and provide information regarding the presence, severity, and distribution of coronary artery disease. Infusion of the $\beta$-receptor agonist dobutamine to pharmacologically induce cardiovascular "stress" in conjunction with echocardiography is a practical method for the cvaluation of cardiac function and the diagnosis of coronary artery disease when the patient is unable to excrcise to adequate levels of cardiovascular stress. In addition to the diagnosis of coronary artery disease, preliminary studies suggest that dobutamine stress echocardiography can provide prognostic information following acute myocardial infarction and an indication of tissue viability for myocardium that is dysfunctional at rest following an acute ischemic event or aborted infarction.

\section{WALI MOTION ANALYSIS}

LV function can be readily assessed using 2-dimensional echocardiography. Utilizing standard parasternal and apical windows, the left ventricle can be imaged and its walls divided into segments for regional wall motion analysis and assessment of global function. The myocardium is conventionally divided into basal, midcavitary, and apical thirds. Circumferentially, the walls are divided into anterior, lateral, posterior, inferior, inferoseptal, and anteroseptal regions. Functional analysis of regional wall motion is used to identify areas as normal, hypokinetic, akinetic, or dyskinetic. In addition, myocardium that is full-thickness is differentiated from that which is thinned, scarred, and aneurysmal. A wall motion score can be generated by combining the scores of individual regions, providing an indication of overall $\mathrm{LV}$ function. In addition, the percentage of normally functioning myocardium can be calculated, providing a quantitative measure of the amount of myocardium that is dysfunctional. 


\section{ECHOCARDIOGRAPHY AND MYOCARDIAL ISCHEMIA}

Surface 2-dimensional echocardiography has been used to assess the location and extent of acute myocardial infarction, as well as to identify patients at high risk following myocardial infarction. This has been possible due to the ability of 2-dimensional cchocardiography to identify areas of myocardium with abnormal systolic function despite normal wall thickness. The fundamental premise of cchocardiographic wall motion analysis is that ischemia or acute infarction results in an abnormal mechanical function of a portion of the left ventricle, which is detected as myocardium that is of normal thickness in diastole but that fails to demonstrate normal systolic thickening. The echocardiographic differentiation of myocardium that is ischemic from that which is recently infarcted is made by monitoring for subsequent functional recovery of that region. Recovery would be suggestive of transicnt ischemia or stunning, whereas permanent regional dysfunction with subsequent thinning and formation of scar is consistent with myocardial infarction and necrosis.

\section{EXERCISE ECHOCARDIOGRAPHY}

The ability to detcct regional wall dysfunction has made 2-dimensional echocardiography a useful adjunct to exercise testing for the diagnosis of coronary artery discase. In 1983, Limacher et al ${ }^{1}$ published data on the use of echocardiography in conjunction with exercise testing in 73 patients. The sensitivity for detecting coronary artery discase based on an abnormal ejection fraction response or the development of regional wall dyssynergia was $91 \%$, with a specificity of $88 \%$. Berberich et $\mathrm{al}^{2}$ published data in 1984 with similar sensitivity and specificity results (94\% for each parameter) for the detection of coronary artery disease using immediate postexercise echocardiography. Compared with electrocardiographic (ECG) monitoring alone during exercise testing, an improvement in accuracy as well as a reduction in nondiagnostic tests with the use of echocardiography was described in 1 serics published by Armstrong et al in $1986^{3}$. In this scries, 35 of 44 patients $(80 \%)$ with normal resting wall motion on echocardiography and significant coronary artery disease on angiography were identified using exercise echocardiography, compared with only $19(43 \%)$ identified using ECG criteria alone. Among those patients without significant coronary artery disease, 13 of 15 $(87 \%)$ were correctly diagnosed with exercise echocardiography, compared with only 8 (53\%) with ECG, and 18 ambiguous exercise ECG results could be reclassified as diagnostic studies by utilizing echocardiographic wall motion analysis.

The sensitivity and specificity of excrcise echocardiography for the diagnosis of coronary artery disease was further evaluated in 123 patients by Armstrong et al in $1987 . .^{4}$ The sensitivity and specificity for the detection of coronary artery disease were $100 \%$ and $72 \%$, respectively, for patients with singlc-vessel disease, and $97 \%$ and $86 \%$, respectively, for patients with multivessel discase. In this serics, exercise echocardiography correctly identified 32 of 59 patients $(54 \%)$ as having multivessel disease. False-negative exercise echocardiograms werc obtained in 12 patients $(10 \%), 8$ of whom had single-vessel coronary artery discase.

In a series published by Ryan et $\mathrm{al}^{5}$ in 1988 , the sensitivity and specificity of exercise echocardiography among 64 patients with normal resting wall motion were found to be $78 \%$ and $100 \%$, respectively. False-ncgative studies were found only among patients with single-vessel disease, and the sensitivity of exercise echocardiography for the detection of single-vessel disease was found to be superior to that of ECG monitoring alone.

The prognostic value of a normal exercise echocardiogram was described by Sawada et al in 1990. ${ }^{6}$ Among 148 patients with normal exercise echocardiograms who were followed for a mean of 28 months, only 6 subsequent cardiac events were noted. All 6 events occurred in patients who achicved $<6$ METS or $<85 \%$ of their predicted maximal heart rate with excrcise. This confirms that a normal cxercise echocardiogram in a patient with good exercise capacity predicts an excellent prognosis with respect to subsequent cardiac events.

\section{NONEXERCISE STRESS ECHOCARDIOGRAPHY}

The inability of a patient to exercise and achicve an adequate heart rate and blood pressure response is a major limitation to exercise stress protocols for the diagnosis of coronary artery disease. Physical limitations to exercise may exist secondary to lung disease, peripheral vascular discase, disorders of the central nervous system, or poor general physical conditioning. In order to circumvent the physical limitations of some paticnts, noninvasive techniques have been developed to provide an assessment for coronary artery disease without the use of excrcise.

Several protocols for noncxercise stress testing in conjunction with echocardiographic wall motion analysis have been described. These include the 
use of static stress modalities such as cold pressor, hand grip, atrial pacing and mental stress, and pharmacologic stress testing including vasodilators such as adenosine and dipyridamole. Inotropic agents such as isoproterenol, dopamine, and dobutamine have also been used for this purpose.

Dipyridamole echocardiography was first described by Picano et al in $1985 .^{7}$ Utilizing the maximal coronary vasodilating effect of dipyridamole on the normal coronary vasculature, regions of myocardial flow inhomogeneity can be provoked in the presence of a coronary stenosis. The coronary flow mismatch is sufficient in some cases to induce a wall motion abnormality that can subsequently be detected on echocardiography. Using this as a marker, the sensitivity of dipyridamole echocardiography for the detection of coronary artery disease has been reported to be $53-88 \%$, with greater sensitivity in the presence of multivessel disease and in patients with regional areas of resting myocardial dyssynergia. ${ }^{8}$

\section{DOBUTAMINE STRESS ECHOCARDIOGRAPHY}

Dobutamine is a $\beta_{1}$ receptor agonist that exerts positive inotropic activity without significant $\alpha$ or $\beta_{2}$ effects. ${ }^{9}$ This results in little effect on peripheral vascular tone and considerably less chronotropic and arrhythmogenic activity than dopamine, norepinephrine, or isoproterenol. It was demonstrated as early as 1976 that dobutamine excrts a differential effect on the perfusion of myocardium supplied by stenotic, as compared with normal, coronary arteries. ${ }^{10}$ In patients without coronary artery disease, dobutamine resulted in a greatly increased coronary arterial perfusion, whereas in patients with significant coronary stenoses, dobutamine infusion resulted in an inhomogeneous pattern of coronary perfusion. As was subsequently described by Fung et al, ${ }^{11}$ dobutamine is an effective agent for precipitating myocardial dysfunction and is therefore well suited for use in stress protocols that rely on the functional assessment of myocardial performance.

Dobutamine stress echocardiography incorporates the usc of 2-dimensional echocardiographic wall motion analysis in the baseline statc and during incremental stages of intravenous dobutamine infusion. Specific protocols vary with respect to precise dosage range and the timing of interval stages. One such protocol involves the use of four 3-minute stages of dobutamine infusion, at doses of $5,10,20$, and $30 \mu \mathrm{g} / \mathrm{kg} / \mathrm{min}$. Heart rate is continuously monitored, and blood pressure and an ECG are recorded at the end of each 3-minute stage. Infusion may be terminated before protocol completion in the event an ischemic response is scen on 2-dimensional cchocardiography or in the event of significant ST-segment depression.

Echocardiographic images are obtained at baseline and at the completion of each stage. Using modern electronic equipment, echocardiographic images obtained at baseline, at $5 \mu \mathrm{g} / \mathrm{kg} / \mathrm{min}$, at peak infusion, and at 5 minutes postinfusion are digitized for display in quad-screen format. Wall motion analysis can be performed with side-by-side comparison of each stage in all echocardiographic views.

The normal echocardiographic pattern of $L V$ wall motion during dobutamine infusion is hyperdynamic myocardial contractility, sometimes resulting in near obliteration of the LV cavity during peak infusion. Depicted in Figure 1 is an example of end-diastolic and end-systolic frames from the parasternal long axis view of a normal patient at baseline and during peak dobutamine infusion of $30 \mu \mathrm{g} / \mathrm{kg} / \mathrm{min}$. Myocardial ischemia during dobutamine infusion is visualized echocardiographically as the induction of a regional wall motion abnormality in a coronary arterial perfusion bcd. Figure 2 depicts end-diastolic and end-systolic frames from a dobutamine stress echocardiogram in a patient with an occluded left circumflex coronary artery. In this example, the posterior wall becomes akinetic at peak dobutamine infusion.

In 1986, Berthe et al $^{12}$ described the use of echocardiographic wall motion analysis during dobutamine infusion to assess for multivessel coronary artery disease in patients following acute myocardial infarction. In this series of 30 patients, dobutamine stress echocardiography correctly identified 11 of 13 patients with multivessel disease, and 15 of 17 patients without coronary discase remote from the area of infarction, yielding a sensitivity and specificity of $85 \%$ and $88 \%$, respectively, for identification of patients with multivessel disease. In 1988, Mannering et al ${ }^{13}$ studied dobutamine stress echocardiography in 50 patients following myocardial infarction. They described a high level of concordance of results between the dobutamine stress echocardiogram and standard cxcrcise treadmill ECG testing.

Several preliminary studies have been reported describing the use of dobutamine stress echocardiography for the detection of coronary artery discase. Mazeika et al $^{14}$ presented a series of 46 patients with suspected coronary artery disease and found a sensitivity of $63 \%$ and a specificity of $93 \%$. For patients with 3 -vessel discase, the sensitivity in this 
FICURE 1. Normal dobutamine stress echocardlogram. End-dlastollc (left) and end-systollc (right) frames of parasternal long-axis vlew of the left ventricle at baseline (top) and peak dobutamine infusion of $30 \mu \mathrm{g} / \mathrm{kg} / \mathrm{min}$ (bottom). The left ventricle demonstrates a normal hyperdynamic "stress" response during dobutamine Infusion.

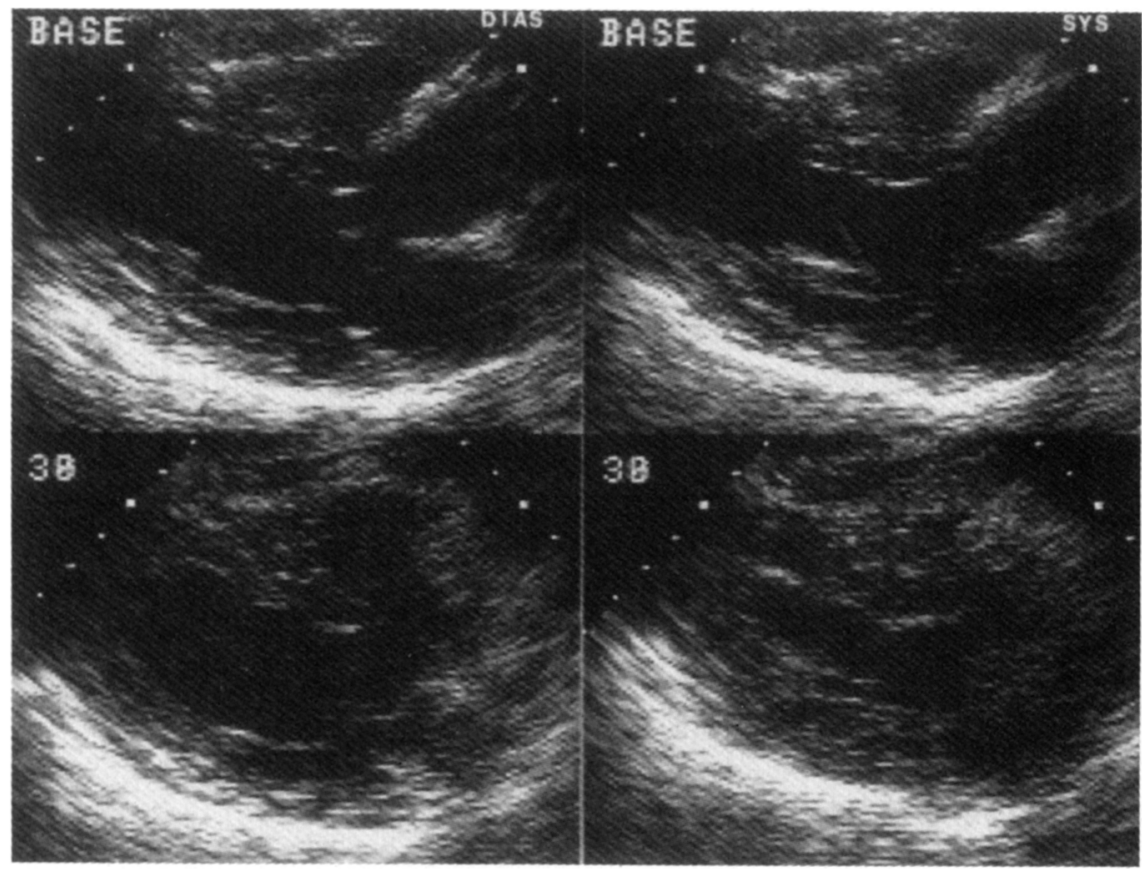

graphy for the detection of coronary artery disease. In this study of 103 patients, dobutamine stress echocardiography was used to assess the presence of coronary artery disease both in patients with normal wall motion at rest and for the presence of remote coronary disease in patients with a resting wall motion abnormality. Among 55 patients with normal resting wall motion, dobutamine stress echocardiography correctly identified 31 of 35 patients with coronary artery disease $(89 \%$ sensitivity) and 17 of 20 patients with no significant coronary artery disease (85\% specificity). Specificity was $100 \%$ for the 14 patients with multivessel
In 1991, Sawada et al ${ }^{16}$ published data f larger series on dobutamine stress echocardio-
FIGURE 2. Abnormal dobutamine stress echocardlogram. End-dlastollc (left) and end-systollc (right) frames of parastemal long-axis view of the left ventricle at baseIne (top) and peak dobutamine Infuslon of $30 \mu \mathrm{g} / \mathrm{kg} / \mathrm{min}$ (bottom). During peak dobutamine infiusion, the posterior wall falls to demonstrate systolic thickenIng-

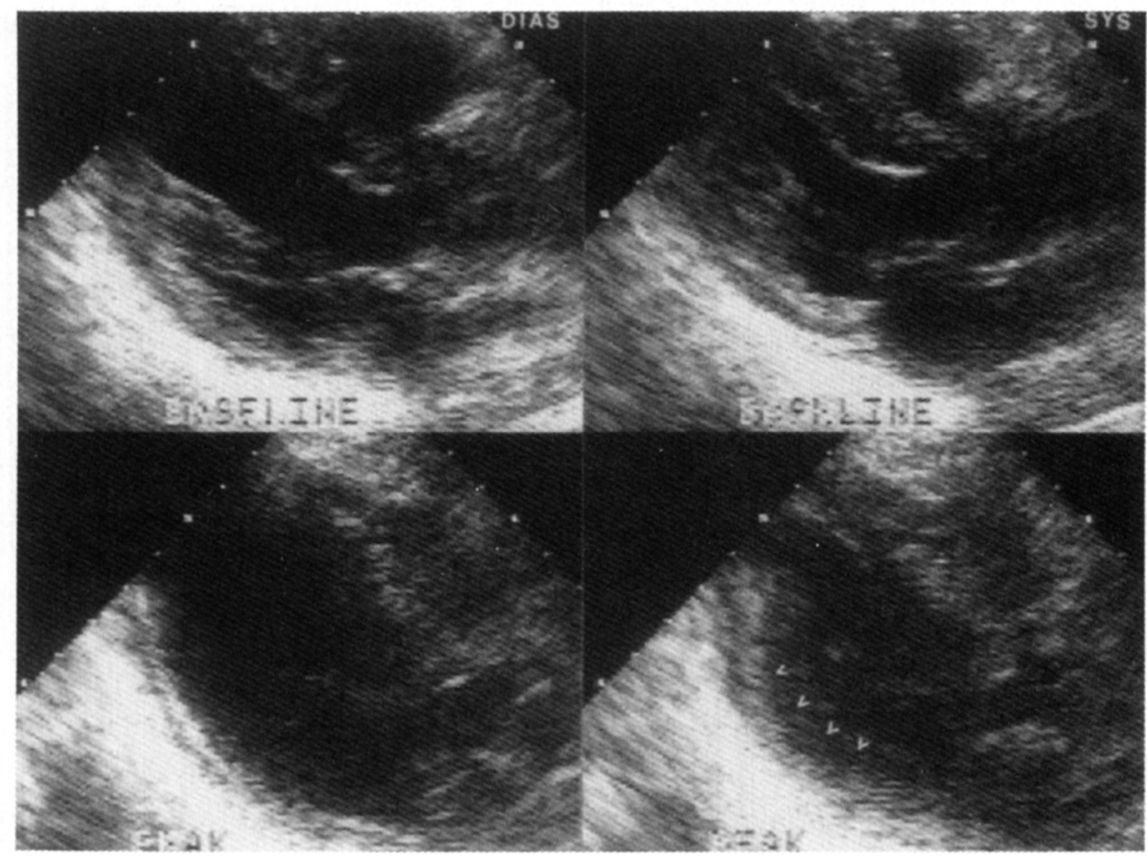


disease, and $81 \%$ for those with single-vessel disease. Among 48 patients with abnormal LV wall motion at rest, dobutamine stress echocardiography correctly identified 21 of 26 patients with remote coronary artery disease ( $81 \%$ sensitivity), and 13 of 15 patients without distant discase $(87 \%$ specificity).

Dobutamine stress echocardiography has been used for the assessment of risk following myocardial infarction. In data published in abstract form by Sawada in 1990, an abnormal dobutamine stress echocardiogram was found to be a sensitive predictor of future cardiac events. ${ }^{17}$ Among 28 patients followed for the development of unstable angina, congestive heart failure, or death for an average of 6.9 months after myocardial infarction, 8 of 9 morbid events occurred in the 17 patients who had a dobutamine stress echocardiogram positive for a new wall motion abnormality consistent with inducible ischemia. Only 1 event occurred among the 11 patients with a negative dobutamine stress echocardiogram.

\section{ECHOCARDIOGRAPHY AND THROMBOLYSIS}

The use of thrombolytic agents has made a marked impact on the subsequent morbidity and mortality following myocardial infarction. The prognosis of the patient and the risk for the development of adverse cardiac events following thrombolytic use during acute myocardial infarction is largely dependent on the size of the infarction and the presence of rcsidually ischemic or jeopardized myocardium. Surface 2-dimensional echocardiography is uniqucly suited to evaluate the location and extent of the initial infarction and the degree of functional recovery, as well as assess for the presence of myocardium that remains ischemic versus that which is viable and at risk of reinfarction after thrombolytic therapy.

Echocardiography has been used to describe an improvement in LV wall motion following reperfusion during acute myocardial infarction. In 1988, Presti et al $^{18}$ described 16 patients treated with angioplasty during acute anterior wall myocardial infarction. Early treatment was associated with a subsequent improvement in echocardiographic wall motion score. Bourdillon $\mathrm{ct}$ al ${ }^{19}$ described a rapid improvement in LV wall motion following reperfusion, seen as early as 1 day and usually maximal at 3 days following reperfusion therapy for acute myocardial infarction. Broderick et al ${ }^{20}$ demonstrated that regional assessment of $\mathrm{LV}$ function by 2-dimensional echocardiography after reperfusion was su- perior to assessment of global function by ejection fraction.

Data from the Thrombolysis in Myocardial Infarction (TIMI) group ${ }^{21}$ have reinforced the need to base any interventional procedures following thrombolysis on the presence of recurrent ischemia, as there appears to be no reduction in morbidity or mortality associated with routine catheterization and angioplasty. On the other hand, the noninvasive evaluation of the presence of inducible ischemia following thrombolytic therapy is problematic: Exercise testing without the use of a concomitant imaging modality is confounded by the evolving ST-segment shifts found after acute myocardial infarction, and reports of the use of exercise or dipyridamole "stress" thallium-201 scintigraphy have been associated with poor sensitivity and specificity for both residual stenoses in the infarct-related artery and for the detection of multivessel disease. ${ }^{22-24}$

Dobutamine stress echocardiography in ischemla following thrombolysis: Limited experience has been reported with the use of dobutamine stress cchocardiography in the evaluation of patients following thrombolytic therapy for acute myocardial infarction. Although the high sensitivity of dobutamine stress echocardiography for the detection of residual stenoses is retained, there is an apparent reduction in the specificity of the test following acute coronary intervention. Preliminary data from 3 series have been presented on the use of dobutamine stress echocardiography following acute intervention during myocardial infarction. The data previously cited by Marcovitz et $a^{15}$ demonstrated a high sensitivity but low specificity for the detection of residual stenoses following coronary intervention. Richards et $\mathrm{al}^{2.3}$ reviewed the results of dobutamine stress echocardiography performed 5-7 days after thrombolytic therapy for acute myocardial infarction in 21 patients who had undergone quantitative coronary arteriography. Wall motion abnormalities were induced in 9 of 10 regions with significant stenoses in the territory of the infarct-related artery, and in 4 of 7 regions corresponding to stenoses in the distribution of noninfarct-related arteries. Howcver, in patients without significant residual stenoses, wall motion abnormalities were inducible in 9 of 11 territories corresponding to the infarct-related artcry and in 21 of 44 territories distinct from the infarct-related artery. As was previously noted, thallium-201 scintigraphy in these patients had a poor specificity that was nearly identical to that of echocardio- 
graphy for the detection of significant coronary obstruction.

In another series published in abstract form, Smart et $\mathrm{al}^{25}$ described the use of dobutamine stress echocardiography in the assessment of multivessel disease or the presence of significant residual stenosis in the infarct-related artery following thrombolytic therapy. A total of 52 patients were studied, 26 of whom had multivessel disease. In this study, the positive and negative predictive values of the dobutamine stress echocardiogram for the presence of multivessel disease were $76 \%$ and $74 \%$, respectively. The prediction of residual stenosis in the infarct-related artery was found to be dependent on the presence of viable myocardium in the infarct zone.

\section{DETERMINATION OF VIABIUTY}

Myocardial stunning following a prolonged ischemic insult is a well-described phenomenon and can be seen after reperfusion therapy. ${ }^{26}$ Although the stunned myocardium is viable, there is a persistent wall motion abnormality early after the ischemic event which eventually improves following reperfusion. In addition to assessing for significant residual stenosis in the infarct-related artery and screening for multivessel disease, the management of patients following thrombolytic therapy necessitates establishing the viability of myocardium in regions with persistent wall motion abnormalities.

There is a physiologic basis for the use of dobutamine stress echocardiography for the assessment of tissue viability after an ischemic insult. In 1984, Ellis et al $^{27}$ described the use of 2-dimensional echocardiography during a low-dose dobutamine infusion $(5-10 \mu \mathrm{g} / \mathrm{kg} / \mathrm{min})$ in an openchest dog model with myocardium salvaged by reperfusion. In this setting, dobutamine infusion resulted in a significant increase in systolic wall thickening in the reperfusion zone both 1 hour and 24 hours after reperfusion. In another study, isoproterenol infusion was studied using technetium-99m angiography 2 weeks after streptokinase administration for myocardial infarction and the results correlated with vessel patency. ${ }^{28}$ Although resting ejection fractions were identical irrespective of vessel patency, there was a significantly greater increase in LV ejection fraction in those patients with a patent infarct-related artery compared with those with persistent occlusion.

These studies provide evidence that, at low doses, inotropic stimulation with $\beta$-receptor agonists will result in an increase in $\mathrm{LV}$ function in areas of viable myocardium but not in areas of myocardial necrosis. Dobutamine stress echocardiography, with a graduated infusion of the $\beta$-receptor agonist dobutamine, is well-suited to provide functional information at incremental levels of inotropic stimulation. The differential response at low doses of dobutamine infusion can be used to distinguish viable (but dysfunctional) from necrotic myocardium and establish tissue viability.

Data supporting the use of dobutamine stress echocardiography for the determination of viability of dysfunctional myocardium following reperfusion in humans come from 2 studies. In 1 study published in 1990, Piérard et al ${ }^{29}$ compared metabolic data from positron emission tomography (PET) and functional response data from early dobutamine stress echocardiography with subsequent wall motion recovery in 17 patients treated with thrombolytic therapy for acute myocardial infarction. In the 5 patients in this study with evidence of tissue glucose metabolism and intact myocardial perfusion on PET scanning, an improvement in regional wall thickening on dobutamine stress echocardiography was noted. All 5 had functional recovery on subsequent examination. Of the 6 patients with no evidence of tissue glucose metabolism on PET, none had a significant improvement in wall motion on either early dobutamine stress echocardiography or on later functional evaluation. Analyzing these data for the predictive value of the early dobutamine stress echocardiogram, none of the 7 patients lacking evidence of myocardial viability on early dobutamine stress echocardiography demonstrated any functional recovery on subsequent evaluation. Of the patients with evidence of myocardial viability on early dobutamine stress echocardiography, 7 of $10(70 \%)$ had subsequent functional recovery. Of the 3 patients who did not have later improvement in wall motion, all had early PET analysis positive for glucose metabolism, indicative of tissue viability.

Smart and colleagues ${ }^{30}$ published a study in abstract form that similarly addresses functional recovery of myocardium in 33 patients following thrombolytic therapy for acute infarction. In this study, 10 of 15 patients (67\%) with improvement of regional wall motion at low doses of dobutamine infusion had subsequent functional recovery. Of 18 patients without evidence of improvement in wall motion on low dose dobutamine infusion, $14(78 \%)$ had no functional improvement on subsequent examination. 


\section{CONCLUSION}

Dobutamine stress cchocardiography is a practical method for the noninvasive assessment for significant coronary artery disease in patients physically unable to exercise. In the absence of a baseline myopathy or prior coronary intervention, it is a sensitive and specific test for the detection of coronary artery discase.

Experience is being gained in using dobutamine stress echocardiography as a tool to cstablish prognosis after myocardial infarction. In addition, dobutamine stress echocardiography appears to be a promising tcchnique for the assessment of tissue viability for myocardium that remains dysfunctional following repcrfusion therapy during acute myocardial infarction.

\section{REFERENCES}

1 Limacher MC, Quinones MA. Poliner I.R, Nelson JG, Winters WL. Waggoner AD. Detection of coronary artery discase with exercise two-dimensional echocardiography: Description of a clinically applicable method and comparison with radionuclide ventriculography. Circulation 1983;67:1211-1218.

2. Berherich SN, Zager JRS, Plotnick GD, Fisher ML. A practical approach to exercise echocardiography; immediate postexercise echocardiography. $I \mathrm{Am}$ Coll Cardial 1984;3:284-290.

3. Armstrong WF, O’Donnell J, Dillon JC, McHenry PI, Morris SN, Feigenbaum II. Complementary valuc of two-dimensional exercise echocardiography to routine treadmill excrcise testing. Ant Intem Med 1986;105:829-835.

4. Armstrong WF, O'Donnell J, Ryan I, Feigenbaum $H$. Fffect of prior myocardial infarction and extent and location of coronary disease on accuracy of exercise echocardiography. $J \mathrm{Am}$ Coll Cardiol 1987;10:531-538.

5. Ryan T, Vasey CG, Presti CF, O'Donncll JA, Feigenbaum H, Armstrong WF. Exercise echocardiography: detection of coronary anery disease in patients with nomal left ventricular wall motion at rest. $J \mathrm{Am}$ Coll Cardiol 1988;11:993-999.

6. Sawada SG, Ryan T, Conley MJ, Corya BC, Feigenbaum H, Armstrong WF. Prognostic value of a normal exercise echocardiogram. Am Hean J 199(),120: $49-55$.

7. Picano E, Distante A, Masini M, Morales MA, Lattanzi F, I'Abbate $\Lambda$ Dipyridamole echocardiography test in effort angina pectoris. A $\mathrm{m}$ Cardiol 1985;56:452-456

8. Picano E, Lattanzi F. Dipyridamole echocardiography. A new diagnostic window on coronary artery discase. Circulation 1991;83(suppl III);III-19-III-26 9. Tuttle RR. Mills J. Development of a new catacholamine to selectively increase cardiac contractility. Circ Res 1975;36:185-1\%.

10. Meyer SL, Curry GC. Donsky MS, Twieg DB, Parkey RW, Willerson JT Influence of dobutamine on hemotynamics and coronary blood flow in patients with and without coronary artery disease. Am J Cardiol 1976;38:103-108.

11 Fung $A Y$, Gallagher KP, Buda AJ. The physiologic basis of dobutamine as compared with dipyridamole stress interventions in the assessment of critical coronary stenosis. Circtuation 1987;76:943-951.

12. Berthe C, Piérard L.A, Hiernaux M, Trotteur G, Lempecreur P, Carlier J, Kulbertus HF. Predicting the extent and location of coronary artery disease in acute myocardial infarction by echocardiography during dobutamine infusion. Am J Cardiot 1986;58:1167-1172.

13. Mannering D, Cripps T, Lcch G, Mehta N, Valantinc H, Gilmore S Bennett $\mathrm{ED}$. The dobutamine stress test as an alternative to exercise testing after acutc myocardial infarction. Br llean $J$ 1988;59:521-526.
14. Mazeika PK, Nadazdin $A$, Oakley CM. Diagnostic accuracy of dobutamine stress echocardiography in coronary discase. (Abstr.) Circulation 199();82:(suppl III):III-195.

15. Marcovitz. PA, Mathias W, Dick RJ, Armstrong WF. Detection of regional coronary stenoses in patients with complex coronary anatomy using dobutamine stress echocardiography. (Ahstr.) J Am Coll Cardiol 1991;17(suppl): 278A.

16. Sawada SG, Segar DS, Ryan T, Brown SE, Dohan AM, Williams R, Fincberg NS, Armstrong WF, Feigenbaum H. Echocardiographic detection of coronary artery discase during dobutamine infusion. Cinculation 1991;83:16051614.

17. Sawada SG, Segar DS, Ryan T, Williams R, Dohan AM, Radtke N, Smart SC, Feigenbaum H. Dobutamine stress echocardiography: Assessment of prognosis after myocardial infarction. Cinculation 1990;82(suppl III):1LI-75.

18. Presti CF, Gentilc R, Armstrong WF, Ryan T, Dillon JC, Feigenbaum H. Improvement in regional wall motion after percutancuus transluminal coronary angioplasty during acute myocardial infarction: utility of two-dimensional echocardiography. Am Hean J 1988;115:1149-1155.

19. Bourdillon PDV, Broderick TM, Williams ES, Davis C, Dillon JC, Armstrong WF, Fineberg $N$, Ryan $T$, Feigenbaum $H$. Larly recovery of regional left ventricular function after reperfusion in acute myocardial infarction assessed by serial two-dimensional eclocardiography. Am J Cardiol 1989;63:641-646.

20. Broderick TM, Bourdillon PDV, Ryan T, Feigenbaum H, Dillon JC, Armstrong WF. Comparison of regional and global left ventricular function by serial echocardiograms after reperfusion in acute myocardial infarction. $\mathrm{J} \mathrm{Am}$ Soc Echocardiogr 1989;2:315-323.

21. The TIMl Study Group. Comparison of invasive and conservative strategies after treatment with intravenous tissuc plasminogen activator in acute myocardial infarction: results of the Thrombolysis in Myocardial Infarction (TIMI) phase II trial. $N$ Engl J Med 1980;320:618-627.

22. Stewart RE, Kander N, Juni JE, Ellis SG, O'Neill WW, Schork MA, Topol EJ, Schwaiger M. Submaximal excrcise thallium-201 SPECT for assessment of interventional therapy in patients with acute myocardial infarction. $\mathrm{Am}$ Heart J 1991;121:1033-1041.

23. Richards FM, Savas V, Schwaiger M, Armstrong WF. Limitations of dobutamine stress echocardingraphy and dipyridamole thallium SPECI after reperfusion therapy for acule myocardial infarction. Cinculation 1990;82(suppl III):III-75

24. Tilkemeier PL, Guiney TE, LaRaia PH, Boucher CA. Prognostic value of predischarge low-level exercise thallium testing after thrombolytic treatment of acule myocardial infarction. Am J Cardiol 199();66:1203-1207.

25. Smart SC. Sawada SG, Ryan T, Segar DS, Bourdillon PDV, Feigenbaum H. Dubutamine echocardiography identifies residual stenosis and multivessel discase after thrombolysis in myocardial infarction. (Abstr.) J Am Coll Cardiol 1991;17(suppl):277A.

26. Braunwald E, Kloner RA. The stunned myocardium: proknged, postischemic ventricular dysfunction. Circulation 1982;66:1146-1149.

27. Ellis SG, Wynne J, Braunwald E, Henschke CI, Sandor T, Kloner RA. Response of reperfusion-salvaged, stunned myocardium to inotropic stimulation. Am Heart $J$ 1984:107:13-19.

28. Satler LF, Kent KM, Fox LM, Goldstein HA, Green CE, Rogers WJ, Pallas RS, Del Negro AA, Pearle DL, Rackley CE. The asseasment of contractile reserve after thrombolytic therapy for acute myocardial infarction. $\mathrm{Am}$ leart J 1986;111:821-825.

29. Piérard LA, DcLandsheere CM, Berthe C, Rigo P, Kulbertus HE. Identification of viable myocardium by echocardiography during dobutamine infusion in patients with myocardial infarction after thrombolytic therapy: comparison with positron emission tomography. J Am Coll Cardiol 1990);15:1021-1031.

30. Smart SC, Sawada SG, Ryan T, Atherton L, Segar DS, Bourdillon PDV, Armstrong WF, Feigenbaum 11. Dobutamine echocardiography predicts recovcry after thrombolysis in myocardial infarction. (Abstr.) Circulation 1990; 82(suppl III):III- 75 . 